\title{
ПРОГРАМНО-АПАРАТНИЙ КОМПЛЕКС ДЛЯ ОЦІККИ ХАРАКТЕРИСТИК КРОВОТОКУ
}

\author{
Феч O.O., студентка \\ ardn@meta.ua \\ Осіпов Р.С., студент \\ roman.osipovvv@gmail.com \\ Козяр В. В., доц. \\ kozyarvasilij@gmail.com \\ Факультет біомедичної інженерії \\ Національний технічний університет \\ «Київський політехнічний інститут імені Ігоря Сікорського» \\ м. Київ, Україна
}

\begin{abstract}
Реферат - Дана робота присвячена розробиі програмно-апаратного комплексу для оцінки параметрів кровотоку в судинах на основі блоку аналогового допплерівського вимірювача швидкості кровотоку, мікропроцесора STM 321432 та середовища розробки NI LabVIEW. Актуальність роботи полягає у перспективі оптимізації морально застарілих засобів діагностичноі техніки, що може створити умови для покращення рівня надання послуг з діагностики та для проведення досліджень в закладах освіти.
\end{abstract}

Ключові слова - ефект Допплера, швидкість кровотоку, допплерографія, віконне перетворення Фур'є, спектрограма, АЦП, uзифрова обробка сигналів, мікропроцесорна техніка.

\section{I. ВСТУП}

Дослідження кровообігу людини, як складної біомеханічної системи, відкриває можливості для діагностики та прогнозування патологічних станів у кардіології. Але динамічний характер досліджуваних процесів, труднощі врахування всіх їх особливостей, сторонні впливи, обмежені можливості техніки ускладнюють діагностику. Актуальним $\epsilon$ удосконалення систем детектування і обробки сигналів діагностичних приладів, що дасть змогу, оптимізуючи існуючі в медичних закладах, а також в закладах освіти, засоби, виявити особливості гемодинаміки і здійснити підтримку прийняття рішень в кардіології.

\section{ІІ. ОГЛЯД ЛІТЕРАТУРИ}

Відомо, що спектр швидкостей в значній мірі залежить від характеру кровотоку в судині і його зміна в часі в різних фазах серцевого циклу надає досліднику більш повну інформацію про стан судин, ніж значення середньої швидкості кровотоку [1].

Основою спектрального аналізу допплерівського зсуву частот $\epsilon$ швидке перетворення Фур'є, яке дозволяє зіставити безперервному сигналу його еквівалентне представлення в частотній області. Основне призначення перетворення Фур'є полягає у виділенні частоти регулярних складових сигналу. Але швидке перетворення Фур'є не здатне передати зміну частоти сигналу в часі, для подолання цього недоліку застосовують віконне перетворення Фур'є (STFT) [3], в якому застосовується операція множення сигналу на вікно перед безпосереднім застосуванням перетворення Фур'є:

$$
\operatorname{STFT}_{f}(\omega, b)=\int_{-\infty}^{\infty} f(x) e^{-i \omega x} w(x-b) d x,
$$


де $w(x-b)$ - вікно, локальна функція, яка зсувається вздовж часової осі для обчислення перетворення в декількох позиціях $b$.

У результаті отримують набір елементарних спектрів інтенсивність-частота, зміна яких у часі відображає зміну швидкості руху елементів крові у судинах. При цьому на екрані допплерівського приладу зміну спектру в часі зображують у вигляді двомірного графіка залежності допплерівського зсуву частот від часу, де інтенсивність сигналу кодують кольором.

Форма спектру надає інформацію про наявність аномалій та геометрію судини, склад крові, роботу серця. Так, розширення спектру вказує на тип потоку: організований потік має малий розкид швидкостей, вузький спектр; дезорганізований - виникає при турбулентності і викликає значне розширення спектру.

На кривій спектра допплерівського зсуву частот виділяють ряд характерних точок [2]. Максимальний підйом кривої відповідає піковій систолічній швидкості кровотоку. Діастолічній швидкості, що передує наступному підйому, відповідає сама нижня точка кривої.

Оцінка характеристик спектральної кривої відбувається за якісними і кількісними показниками. До кількісних характеристик допплерівського спектра відносять значення швидкостей та індексів.

Найважливішими

кількісними характеристиками допплерівського спектра [4] є: пікова систолічна швидкість, середня, кінцева діастолічна швидкості, систолодіастолічний, пульсаторний індекси і індекс резистентності. Практичне значення вимірювання пікової систолічної швидкості в тому, що цей показник істотно змінюється при стенозах. Для багатьох судин встановлені його значення, що дозволяє відрізнити нормальний i патологічний кровоток i визначити орієнтовну ступінь стенозу. Середня швидкість залежить від способу виміру та, як правило, не має практичного значення i використовується в основному для розрахунку пульсаторного індексу і об'ємної швидкості кровотоку. Основне значення наведених вище індексів полягає в кількісній оцінці периферійного судинного опору.
Можливе вивчення і, при необхідності, обчислення ще більшого числа показників, однак, в повсякденній практиці вони не застосовуються.

\section{III. МЕТА ДОСЛІДЖЕННЯ}

\begin{tabular}{|c|c|}
\hline \multicolumn{2}{|r|}{ програмно-апар } \\
\hline комплексу & аналоговог \\
\hline допплерівського & вимірювача \\
\hline
\end{tabular}

\section{IV. МАТЕРІАЛИ}

Для обробки сигналу було запропоновано використовувати середовище розробки NI LabVIEW 2020. Моделювання та розробка схеми пониження напруги проводилося в середовищі розробки МicroСap 12 та DipTrace. Перевірка роботи друкованої плати проводилася 3 використанням PcLab2000LT. Для здійснення аналогоцифрового перетворення вхідного сигналу був використаний мікропроцесор STM 321432kcu.

\section{V. РЕЗУЛЬТАТИ ТА ОБГОВОРЕННЯ}

У зв'язку з потребою створення приладу спряження між вимірювачем швидкості кровотоку, що $\epsilon$ аналоговим приладом, та розроблюваним програмним забезпеченням (рис.1) для аналізу спектру кровотоку, постає необхідність створити аналого-цифровий перетворювач (АЦП).

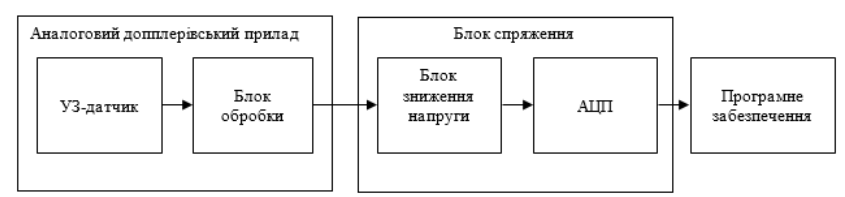

Рис. 1. Блок-схема розроблюваного програмноапаратного комплексу

Оскільки вихідний сигнал приладу коливається в межах від -12 В до +12 В, а більшість АЦП працюють 3 сигналом від 0 В до 5 або 3 В, необхідно створити блок зниження напруги з можливістю налаштування діапазону вихідної напруги.

Електрична схема пониження напруги була створена в МicroCap 12 (рис.2). 
Змінюючи номінали резисторів R5 i R6 можна регулювати діапазон вихідної напруги схеми. Дана схема представлена для одного каналу допплерівського приладу.

Діапазон напруги на виході від 0,7 В до 2,5 В (рис.3) при вхідній напрузі від -12 В до 12 В, що дасть змогу, за необхідності, використовувати АЦП, побудований на іншому мікропроцесорі, або, змінивши значення опорного сигналу, використати для оцифровки сигналу лінійний вхід звукової карти персонального комп'ютера.
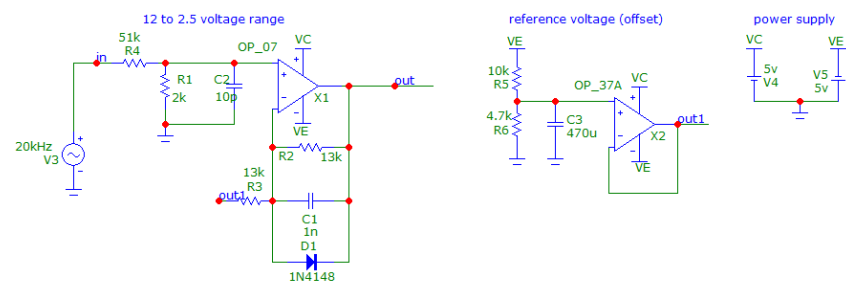

Рис. 2. Електрична схема пониження напруги

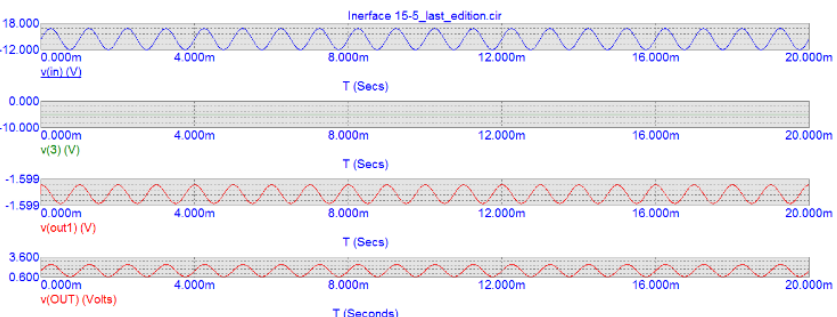

Рис. 3. Аналіз перехідних процесів у середовищі MicroCap 12, зверху вниз: вхідний сигнал 12 В, джерело -5 В, опорний сигнал 1,6 В, вихідний сигнал 2,5 В

За допомогою лінійної апроксимації побудованого графіку залежності напруги на виході схеми від напруги вхідного сигналу (рис.4), що був отриманий за допомогою функції Stepping в режимі аналізу перехідних процесів, було отримано вираз для розрахунку вихідної напруги:

$$
y=-0,0755 x+2,5798
$$

де $y$ - напруга на виході схеми, В;

$x$ - напруга вхідного сигналу, В.

Загалом, зміні амплітуди вхідного сигналу на 1 В відповідає зміна амплітуди вихідного сигналу на 0,076 В.

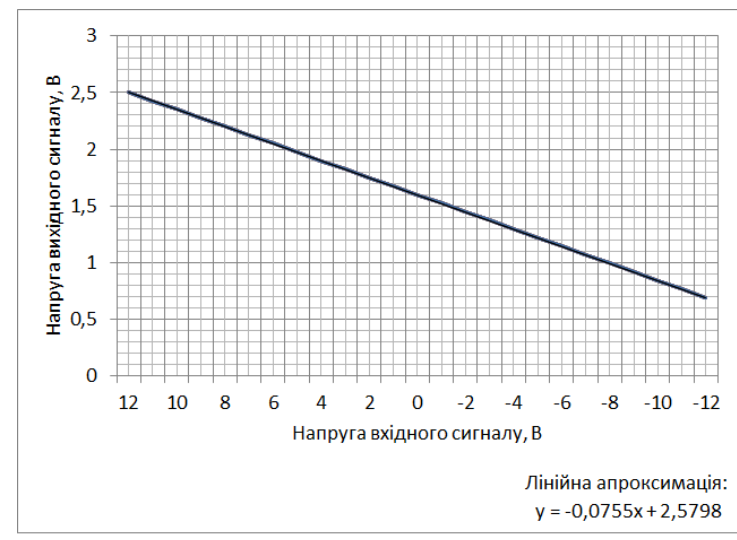

Рис. 4. Електрична схема пониження напруги

Для того, щоб оцінити роботу схеми, враховуючи допуски номіналів іiі елементів, був застосований аналіз Монте-Карло. При такому аналізі кожна схема моделюється 3 компонентів, параметри яких можуть приймати випадкове значення по певному закону розподілу у межах заданого допуску [5].

Налаштування, які були обрані виходячи з рекомендацій [6]: тип розподілу worst case (генерує компоненти $3 \quad 50 \%$ ймовірністю отримати мінімум і максимум параметру), кількість запусків - 300 разів, допуски номіналів - 1\%. Допуски були задані відповідно до технічного опису обраних елементів за допомогою команди MODEL.

При встановлені допуску 1\% діапазон амплітудних значень вихідної величини на гістограмі розподілу доволі вузький i обмежується проміжком від 2,42 В до 2,62 В (рис.5), візуально оцінити розкид значень вихідної величини можна з аналізу перехідних процесів (рис.6).

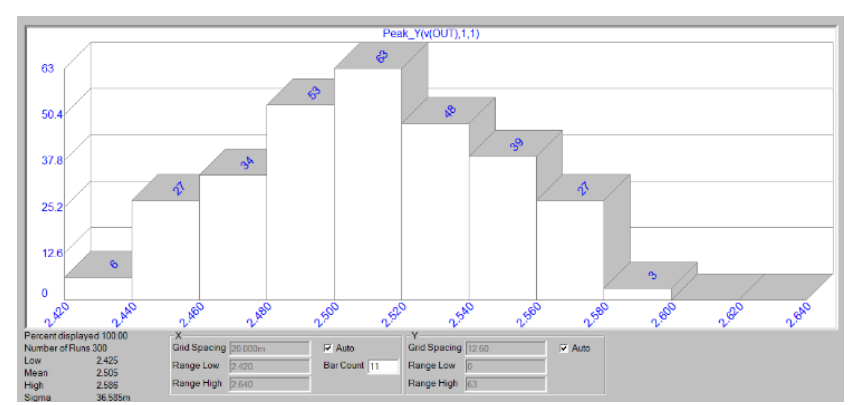

Рис. 5. Гістограма розподілу амплітудних значень напруги для аналізу Монте-Карло 


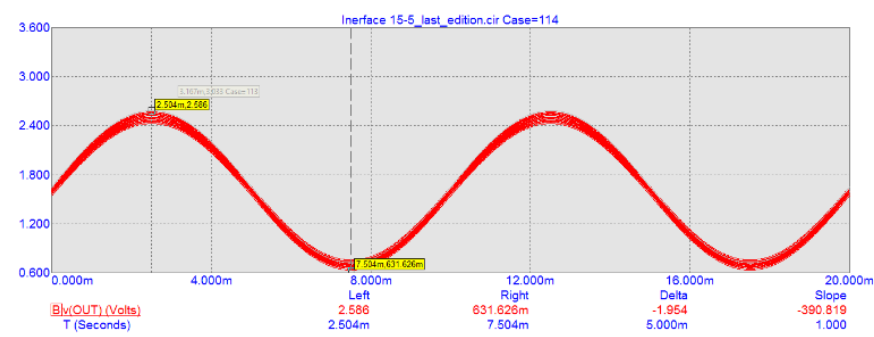

Рис. 6. Аналіз Монте-Карло для перехідних процесів

Принципова електрична схема була перенесена до середовища розробки DipTrace для подальшої розробки макету друкованої плати і іï реалізації.

Перевірка

функціонування

виготовленої друкованої плати проводилась із використанням осцилографу PCSGU250, 3 генератору якого подавалися сигнали на один 3 вхідних каналів схеми: ступінчатий 3 напругою від -5 В до 5 В та частотою 100 Гц (рис.7), наростаючий 3 напругою від $0 \mathrm{~B}$ до $10 \mathrm{~B}$ та частотою 100 Гц (рис.8). Ціна поділки шкали $0,2 \mathrm{~B}$.

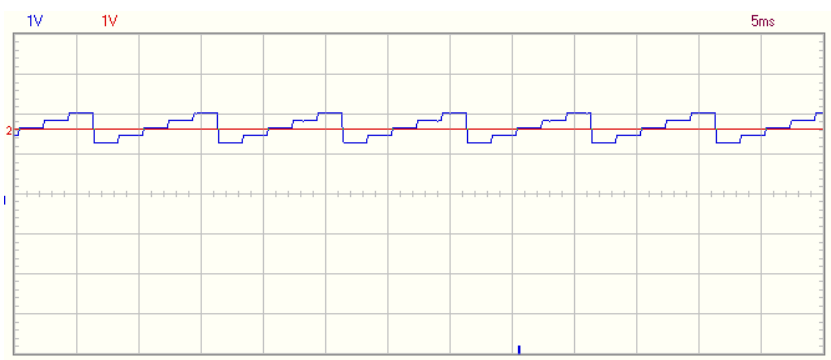

Рис. 7. Реакція схеми на ступінчатий сигнал: $1 \mathrm{~V}-$ вихідна напруга, $2 \mathrm{~V}$ - середня точка 1,6 B

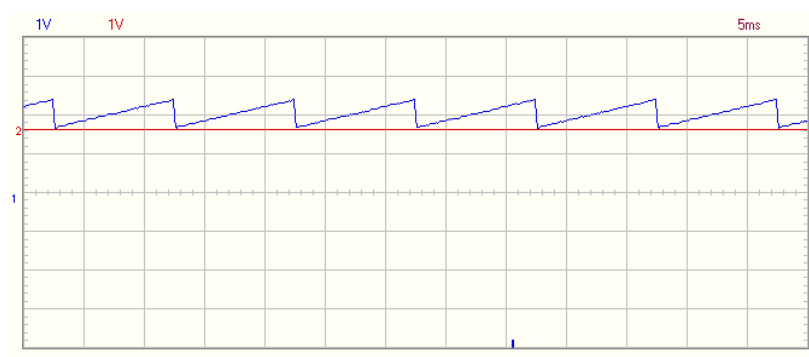

Рис. 8. Реакція схеми на наростаючий сигнал: $1 \mathrm{~V}-$ вихідна напруга, $2 \mathrm{~V}$ - середня точка $1,6 \mathrm{~B}$

Отримані результати повторюють очікувані значення напруги на виході, отримані при моделювання роботи електричної схеми в МicroCap 12 в режимі аналізу перехідних процесів Transient.

Обраний для реалізації АЦП мікропроцесор STM 321432 здатний оцифровувати аналоговий сигнал напругою до 3,3 В. Його основні характеристики наступні: живлення - від 1,71 В до 3,6 В, тип АЦП- послідовного наближення, при роздільній здатності - 12 біт маємо 5,33 Msps (час дискретизації - до 18,75 нс), чого цілком достатньо для запланованої області застосування.

Для зчитування даних 3 мікроконтролера були застосовані об'єкти палітри віртуального інструменту VISA у середовищі розробки NI LabVIEW (рис.9).

Для дослідження спектру був створений тестовий віртуальний прилад, основу якого складає підприлад STFT (short-time Fourier transformation) Spectrogram, що здійснює віконне перетворення Фур'є [7], тобто розбиває вхідний сигнал на рівні проміжки, що відповідають ширині вікна, i здійснює перетворення Фур'є в кожному, таким чином надаючи можливість спостерігати зміну частоти та інтенсивності сигналу в часі. Підприлад повертає 2D-масив, що описує розподіл енергії сигналу в частотно-часовій області. Кожний рядок відповідає миттєвому спектру потужності в певний час.

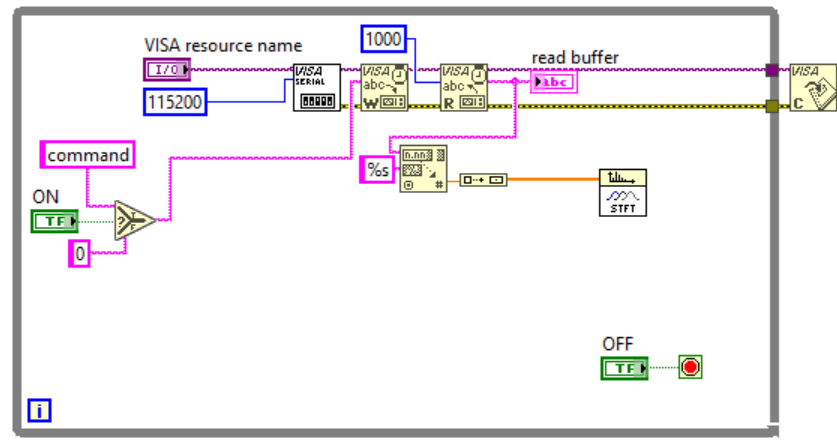

Рис. 9. Віртуальний підприлад зчитування даних 3 мікроконтролера

Результат демонструється у вигляді графіку залежності частота-час-інтенсивність, де інтенсивність кодується кольором на графіку Intensity Graph або на графіку 3D Mesh.

Створені блоки віртуального приладу дозволяють розраховувати швидкість (рис.10) i основні параметри кровотоку (рис.11) та виводити їх значення. 


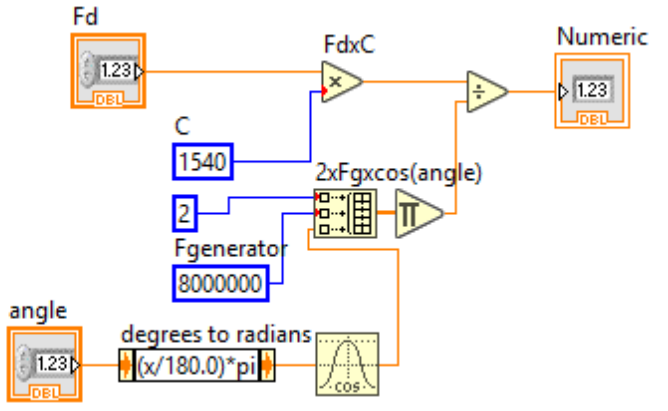

Рис. 10. Код для розрахунку швидкості

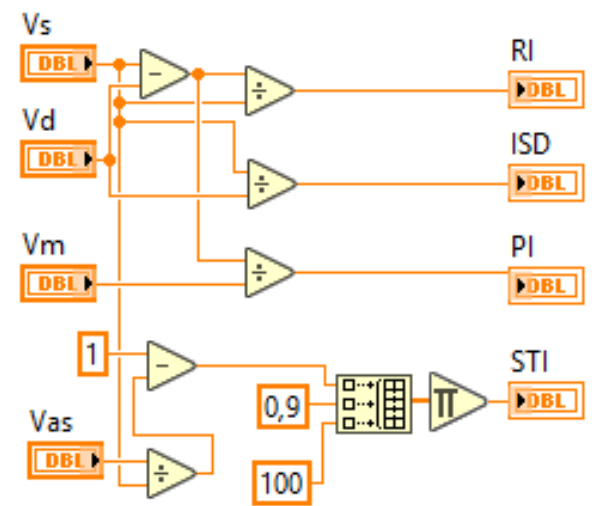

Рис. 11. Код для розрахунку індексів

Для перевірки роботи основного блоку 3 віконним перетворенням Фур'є використовувався сигнал зі змінною частотою, яка приймала значення від 1 Гц до 0,5 Гц (рис.12).

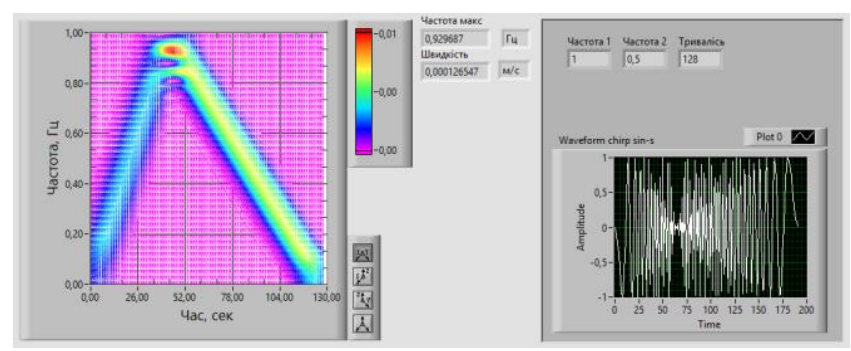

Рис. 12. Тестуванні коду з сигналом змінної частоти

При цьому варто зазначити, що стали очевидними основні недоліки віконного перетворення Фур'є, а саме: при обчисленні використовується фіксоване вікно, яке не може бути адаптоване до локальних властивостей сигналу [8], неможливість налаштувати одночасно високу роздільна здатність і за часом, і за частотою, виникнення принципу невизначеності Гейзенберга, в основі якого той факт, що неможливо сказати точно, яка частота присутня в сигналі в даний момент часу (можна говорити тільки про діапазон частот) i не можливо сказати в який точно момент часу частота присутня в сигналі (можна говорити лише про період часу).

3 усього вищесказаного можна зробити висновок, що подальша робота над програмним забезпеченням може включати в себе також створення блоку спектрального аналізу на основі вейвлет перетворення, яке долає проблему виникнення невизначеності Гейзенберга i, отже, може бути запропонованим до використання.

\section{VI. ВИСНОВКИ}

1. Спроектований програмноапаратний комплекс розрахований на два канали для сигналів прямого i зворотного кровотоку допплерівського приладу та призначений для отримання спектру частот $\mathrm{i}$ здійснення подальших розрахунків основних швидкостей та індексів.

2. Основні складові програмноапаратного комплексу наступні: блок аналогового допплерівського приладу, блок спряження, що складається зі схеми пониження напруги та АЦП на мікропроцесорі STM $321432 \mathrm{kcu}$, програмне забезпечення в NI LabVIEW 2020.

3. Блок пониження напруги має наступні характеристики: коефіцієнт зниження напруги $-4,8$; середня точка вихідного сигналу - 1,6 В; діапазон вихідних напруг - від 0,7 В до 2,5 В. Тестування блоку підтвердили результати моделювання схеми.

4. Моделювання роботи програмного забезпечення показало, що розроблений комплекс потребує подальшого вдосконалення і проведення тестування на прототипі реального сигналу або його моделі.

\section{ПЕРЕЛІК ПОСИЛАНЬ}

[1] Осипов Л.В. Ультразвуковые диагностические приборы. Режимы, методы и технологии/ Л.В. Осипов. - Москва: Изомед, 2011. - 316 с.

[2] Маліков Антон Геннадійович. Застосування ефекту доплера для діагностики кінцівок людини: дис.магістра: 534-14/ Маліков Антон Геннадійович. Київ, 2018. - 97 с.

[3] Берестень Н.Ф., Цыпунов А.О. Допплеросонография периферических сосудов. Часть I (опыт применения УЗИ сканеров фирмы "Медисон" в скрининговых исследованиях)/ Н.Ф.Берестень, А.О.Цыпунов // SonoAce International. - 1999. - № 4. - c. 83-90. 
[4] Лаптєв О.А. Порівняний аналіз методів розпізнавання сигналів радіозакладних пристроїв на основі частотних перетворень. / О.А. Лаптєв // Телекомунікаційні та інформаційні технології. - 2019. - № 3 (64). - c. 71-82.

[5] Амелина М.А., Амелин С.А. Программа схемотехнического моделирования Micro-Cap. Версия 9,10. - Смоленск, Смоленский филиал НИУ МЭИ, 2012. - 617 с., ил.

[6] Micro-Cap 12 Electronic Circuit Analysis Program User's Guide, Twelfth Edition, June 2018. [Електронний pecypc] // Spectrum Software: [сайт]. - Режим доступу: spectrum-soft.com/download/ug12.pdf. - Назва 3 екрана.

[7] Tatsuro Baba. Time-Frequency Analysis Using Short Time Fourier Transform./ Tatsuro Baba. // The Open Acoustics Journal. - 2012. - № 5. - p. 32-38.

[8] П. Д. Лежнюк, О. О. Мірошник. Застосування перетворень фур'є та вейвлетспектрограм для ідентифікації спотворень режимів роботи розподільних мереж 0,38/0,22 кВ. / П. Д. Лежнюк, О. О. Мірошник. // Вісник Вінницького політехнічного інституту. - 2015. - № 1. - с.71-79. 


\title{
ПРОГРАММНО-АППАРАТНЫЙ КОМПЛЕКС ДЛЯ ОЦЕНКИ ХАРАКТЕРИСТИК КРОВОТОКА
}

\author{
Феч O.O., студентка \\ ardn@meta.ua \\ Осипов Р.C., студент \\ roman.osipovvv@gmail.com \\ Козяр В. В., доцент \\ kozyarvasilij@gmail.com \\ Факультет биомедицинской инженерии \\ Национальный технический университет \\ «Киевский политехнический институт имени Игоря Сикорского» \\ м. Киев, Украина
}

Реферат - Данная работа посвящена разработке программно-аппаратного комплекса для оченки параметров кровотока в сосудах на основе блока аналогового допплеровского измерителя скорости кровотока, микропроцессора STM $321432 \mathrm{kcu}$ и среды разработки NI LabVIEW. Актуальность работь заключается в перспективе оптимизачии морально устаревших средств диагностической техники, что может создать условия для улучшения уровня предоставления услуг по диагностике и для проведения исследований в учебных заведениях.

Ключевые слова - эффект Допплера, скорость кровотока, допплерография, оконное преобразование Фурье, спектрограмма, АЦП, иифровая обработка сигналов, микропрочессорная техника.

UDC 612.15, 004.31

\section{SOFTWARE AND HARDWARE COMPLEX FOR ASSESSMENT OF BLOOD FLOW CHARACTERISTICS}

O. Fech, student ardn@meta.ua

R. Osipov, student roman.osipovvv@gmail.com

V. Kozyar., docent kozyarvasilij@gmail.com Faculty of Biomedical Engineering National Technical University "Kyiv Polytechnic Institute named after Igor Sikorsky" Kiev, Ukraine

\begin{abstract}
The work is devoted to the development of software and hardware for estimating blood flow parameters in vessels based on the block of analog Doppler blood flow meter, microprocessor STM $321432 \mathrm{kcu}$ and development environment NI LabVIEW. The urgency of the work lies in the prospect of optimizing obsolete diagnostic equipment, which can create conditions for improving the level of diagnostic services and for research in educational institutions.
\end{abstract}

Key words - Doppler effect, blood flow velocity, Doppler sonography, Short-time Fourier transformation, spectrogram, ADC, digital signal processing, microprocessor technology. 